\title{
The Impact of Analyst-Induced Misinformation on the Requirements Elicitation Process
}

\author{
Radha Appan \\ Cleveland State University, r.appan@csuohio.edu \\ Glenn J. Browne \\ Texas Tech University, glenn.browne@ttu.edu
}

Follow this and additional works at: https://engagedscholarship.csuohio.edu/bus_facpub

Part of the Management Information Systems Commons

How does access to this work benefit you? Let us know!

Publisher's Statement

Copyright University of Minnesota, Management Information Systems Research Center

\section{Original Published Citation}

Appan, R., Browne, G. J. (2012). The Impact of Analyst-Induced Misinformation on the Requirements Elicitation Process. MIS Quarterly, 36(1), pp. 85-106.

This Article is brought to you for free and open access by the Monte Ahuja College of Business at EngagedScholarship@CSU. It has been accepted for inclusion in Business Faculty Publications by an authorized administrator of EngagedScholarship@CSU. For more information, please contact library.es@csuohio.edu. 


\title{
THE IMPACT OF ANALYST-INDUCED MISINFORMATION ON the ReQuiRements Elicitation PROCEss ${ }^{1}$
}

\author{
Radha Appan \\ Nance College of Business Administration, Cleveland State University, 2121 Euclid Avenue, \\ Cleveland, $\mathrm{OH} 44115$ U.S.A. \{r.appan@csuohio.edu\}

\section{Glenn J. Browne} \\ Rawls College of Business Administration, Texas Tech University, Lubbock, TX 79409 U.S.A. \{glenn.browne@ttu.edu\}
}

\begin{abstract}
Information requirements determination (IRD) is concerned with developing accurate requirements for a proposed system, primarily by eliciting information from users and other organizational stakeholders. In this paper we build and test theory concerning a significant threat to the accuracy of information requirements, termed the misinformation effect. Misinformation is distorted, false, or other erroneous or misleading information that does not reflect the true state of the world or state of mind of the person communicating the information. The misinformation effect refers to the tendency of people to recall misleading or false information introduced to them following an event instead of original material learned or observed at the time the event occurred. During user-analyst communication in the IRD process, analysts may introduce misinformation in their discussions with users. We use the misinformation effect literature to hypothesize that in such circumstances users are likely to recall misinformation introduced by analysts rather than their true beliefs and knowledge of facts. Additionally, we use literature in social psychology to hypothesize that the misinformation effect will be stronger when misinformation is introduced using a social technique rather than a nonsocial technique. We conducted an experiment to test the misinformation effect in the requirements elicitation process. Results indicated that (1) introduction of misinformation reduces the accuracy of requirements provided by users, and (2) social techniques (interviews) are more vulnerable to the misinformation effect than nonsocial techniques (surveys). Our research contributes to the information systems literature by identifying an important reason that requirements provided by users may be inaccurate, and to IRD practice by identifying important dilemmas caused by the misinformation effect as well as potential solutions. We also contribute to the psychology literature by demonstrating the existence of the misinformation effect with users' experiential factual knowledge and beliefs in a business context, and by aiding in understanding the underlying causes of the misinformation effect. We discuss implications of our findings and directions for future research to address challenges resulting from the misinformation effect.
\end{abstract}

Keywords: Information requirements determination, misinformation effect, user-analyst communication, user participation, elicitation techniques, systems development

\footnotetext{
${ }^{1}$ Alan Dennis was the accepting senior editor for this paper. Andrew Burton-Jones served as the associate editor.
} 


\section{Introduction}

Systems development success is highly contingent on the accuracy of requirements gathered from users and other stakeholders during the information requirements determination (IRD) process (Davis 1982; Hickey and Davis 2004; Wetherbe 1991). The accuracy of requirements depends in large part on the effectiveness of the communication between the systems analyst and the users (Bostrom 1989; Gallivan and Keil 2003; Hanssen and Faegre 2008; He and King 2008; Valusek and Fryback 1987). In this paper we build and test theory concerning a significant threat to the accuracy of information requirements that occurs during user-analyst communication, termed the misinformation effect.

Misinformation refers to distorted, false, or other erroneous or misleading information that does not reflect the true state of the world or true state of mind of the person communicating the information (Fox 1983; Zhou and Zhang 2007). Misinformation is a general phenomenon in human behavior, as people provide misinformation unintentionally or intentionally (that is, by lying) all the time (see, e.g., DePaulo et al. 1996). The misinformation effect refers to the tendency to recall misleading or false post-event information instead of original material learned or observed at the time an event occurred (Loftus 1979, 2005; Loftus, Miller, and Burns 1978; Saunders and MacLeod 2002). Research has demonstrated that the introduction of cues containing misinformation (misleading or erroneous information), for example, to an eyewitness to an event, can lead to subsequent recall of this misinformation rather than the information that was originally observed and committed to memory (Gabbert et al. 2004; Johnson 1994; Saunders and MacLeod 2002). The effect has been investigated extensively in the context of eyewitness memory, memory for autobiographical events, memory for semantic information (e.g., word pairs), and memory of customers for product-related stimuli. However, the impact of the misinformation effect on an individual's beliefs and his or her ability to recall factual information learned over a period of time, which are the types of information elicited during IRD, have not been investigated.

Requirements determination is a key stage of systems development, since so many subsequent activities depend on accurate requirements. There are numerous methodologies that can be applied to gather requirements, and different assumptions are made in each methodology. In this paper, we research the situation in which a systems analyst has primary control over the requirements determination process and elicits requirements from traditional software users. Regardless of methodological approach and assumptions, there are several reasons to believe that the IRD process is highly vulnerable to the misinformation effect. First, analysts and users often have different mental models and speak "different languages," both of which increase the likelihood of communicating misinformation (Alvarez 2002; Bednar and Welch 2008; Bostrom 1989; Browne and Ramesh 2002; Orlikowski and Gash 1994). Second, requirements elicitation necessarily requires considerable recall of information by users, regardless of whether they are being interviewed or surveyed or are reacting to prototypes (Byrd et al. 1992; Davis 1982; Jain et al. 2003; Moody et al. 1998). As noted, recall processes have been shown to be vulnerable to the misinformation effect. Finally, for motivational reasons, analysts may consciously or subconsciously introduce misinformation to influence users to agree with them (Alvarez 2002; Lin and Silva 2005; Markus and Bjørn-Andersen 1987; Myers and Young 1997; Robey and Markus 1984). Thus, it is critical to examine the potential impact of misinformation on the information acquired during IRD. If the misinformation effect is observed, it will have important implications for the design of elicitation techniques, strategies for technique selection, user participation during IRD, and user-analyst communication in general.

Our investigation has three goals. First, we use the misinformation effect literature to develop our own theoretical basis to argue that when asked to provide requirements, users are likely to recall misinformation introduced by analysts rather than their true beliefs and knowledge of facts. Second, we seek to develop an improved understanding of the misinformation effect by exploring the underlying causes of the phenomenon during the requirements elicitation process. Specifically, we explore whether the phenomenon is due to inherent cognitive limitations of humans (Loftus 1979) or is caused by the common desire of individuals to appear to be in agreement with others (Tajfel and Turner 1986). Third, we investigate the differences between social (interviews) and nonsocial (surveys) elicitation techniques when misinformation is present. All three goals are aimed at building and testing theory. The first and third goals have not been investigated empirically before in any context. The second goal is new to the systems development literature and will help build a better theoretical understanding of various phenomena in IRD and systems development generally.

The rest of the paper is organized as follows. The next sections provide background and describe our theoretical argument as to why the IRD process is susceptible to the misinformation effect. Next, the methodology for the study is described, followed by the results of an experiment. The paper concludes with implications of the findings for theory and practice. 


\section{Background}

\section{Information Requirements Determination in Systems Development}

Information requirements determination is the process by which systems analysts assess and model the needs for a proposed information system (Davis 1982; Wetherbe 1991). In most systems development efforts, the primary source of requirements is people who use the current system and/or who will use the proposed system. Common methods for eliciting requirements include personal interviews, surveys or questionnaires, observation, joint application development (JAD) sessions, and protocol analysis (Goguen and Linde 1993; Kendall and Kendall 2010; Liou and Chen 1994; Robertson and Robertson 1999). The requirements determination process thus may involve both social (e.g., interviews) and nonsocial (e.g., surveys) techniques.

Studies that have emphasized the role of analysts in facilitating and improving requirements elicitation have focused primarily on the elicitation techniques that can be employed, such as structured and unstructured interviews, protocol analysis, laddered grids, and card sorting (Agarwal and Tanniru 1990; Burton et al. 1987; Moody et al. 1998). Although these studies recognize the need to understand how humans store and use knowledge to facilitate recall of accurate requirements (Best 1989), they do not emphasize the need to understand factors that inhibit users' ability to provide accurate requirements. Although there are many possible causes of inaccurate requirements (e.g., lack of communication among the relevant parties, inability of users to articulate requirements, unwillingness of users to provide requirements), misinformation potentially inhibits accurate requirements, and that is our focus in the current study.

Requirements can be elicited throughout the systems development process, and new requirements sometimes emerge even late in the process. In systems development methodologies that use well-defined stages, typically termed waterfall or planned methods, the primary requirements gathering occurs during the analysis phase, after systems planning and selection and before systems design (George et al. 2006). In development methodologies often referred to collectively as agile, requirements are gathered on an on-going basis as users react to prototypes or other types of models of the proposed software (e.g., Baskerville and Pries-Heje 2004; Beck 1999; Boehm 2002; Lee and Xia 2010) (although it should be noted that even agile methods typically start by gathering a basic set of requirements). Both waterfall and agile methods are used extensively in contemporary systems development. Although agile methods have grown in popularity over the past decade and continue to grow, industry surveys show that the waterfall methodology is still used in a large majority of systems development projects; mature agile development methods are reportedly used in only 15 to 25 percent of projects (Light 2009; Norton 2008). As a basic psychological phenomenon, the misinformation effect, if it occurs, should be present in any type of development methodology. However, in the present research we assume the use of a waterfall methodology. We include implications of our findings for agile methodologies in the discussion section.

\section{User-Analyst Communication in IRD}

The success of the IRD process depends to a great extent on users and other stakeholders communicating accurate requirements to analysts. Prior studies have emphasized the importance of user participation for improving the IRD process and ultimate system success (Hunton and Beeler 1997; Hwang and Thorn 1999; Newman and Sabherwal 1996). However, empirical results of studies examining the role of user participation have been mixed, and researchers now recognize that the impact of user participation is dependent upon numerous contingency factors (Gallivan and Keil 2003; Hartwick and Barki 1994; Hunton and Beeler 1997; McKeen et al. 1994). One such factor that has been recognized as essential for productive user participation is effective communication between users and analysts. However, models of user participation usually assume that effective communication occurs and thus do not fully describe the user-analyst communication process (Gallivan and Keil 2003; Hartwick and Barki 2001; Hunton and Beeler 1997; Newman and Noble 1990; Robey et al. 1989).

Gallivan and Keil (2003) proposed a four-stage process model of communication between users and analysts. In their model, the first two stages of the communication (users formulate the message and users transmit the message) primarily involve users' cognition, while the last two stages (analysts receive and interpret the message, and analysts set priorities and take action) involve the cognitions and behavior of analysts. One important consideration not highlighted by Gallivan and Keil is that users' formulation of the message to be communicated to the analysts is affected by the cues used by the analysts. Specifically, users' formulation of the message is largely contingent on their ability to recall relevant information, and their ability to recall relevant information is influenced by the cues provided by the analysts. Any erroneous information (misinformation) in the cues provided by the analyst could result in users providing inaccurate requirements consistent with the misinformation in the cues. This inaccurate information may then make its way into requirements documents and system design. 


\section{Misinformation Effect}

The misinformation effect has traditionally been examined in the context of eyewitnesses' memory for the details of a witnessed event. The misinformation effect involves misreporting of information as a result of exposure to misleading information received after the actual event (Loftus et al. 1989). For example, a pedestrian who witnesses an auto accident (event of interest) may be interviewed by the police after the accident. During the interview (post-event), the interviewer may incorrectly suggest (e.g., in a leading question) that the vehicle involved in the accident encountered a stop sign, when in fact only a yield sign was present. During subsequent interviews, the eyewitness is likely to recall the stop sign rather than the yield sign (Loftus, Miller, and Burns 1978). This exemplifies the misinformation effect.

Much research has demonstrated that exposure to post-event information can lead to distortion of eyewitnesses' memories (Bekerian and Bowers 1983; Belli 1988; Bonto and Payne 1991; Ceci et al. 1988; Wagenaar and Boer 1987; Zaragoza et al. 1987). The findings of this stream of research have had important implications for the legal system, which recognizes, for example, the need to sequester witnesses while others testify to avoid memory impairment (Federal Rules of Evidence §615). Evidence of the misinformation effect in the eyewitness memory paradigm has triggered research in several other domains interested in human memory and recall. For instance, research on autobiographical memory has demonstrated that inconsistent information learned subsequent to the original event can explain some of the common errors that arise during recall of autobiographical events (Neisser 1981; Schooler and Tanaka 1991). Similar results have been found in studies involving tests of memory for semantic information (Saunders and MacLeod 2002). Recently, findings from the misinformation literature have been extended to studies on advertising. In this context, it has been found that post-experience advertisements alter episodic information learned by a consumer during direct experience (e.g., tasting a sample of orange juice), and thus the misinformation effect concept has had important implications for social policy on deceptive advertising (Braun and Loftus 1998; Cowley and Janus 2004). In sum, numerous empirical studies have established the presence of the misinformation effect during recall, and there is little doubt that misleading information presented to people leads to erroneous reporting of actual event-related information.

Although the IRD process relies to a great extent on the ability of users to recall accurate requirements, the implications of the misinformation effect on requirements gathered during IRD have not been examined. The IRD process involves recall not only from episodic memory (similar to what is examined in the eyewitness memory and other paradigms) but also beliefs of users formed over a period of time and knowledge of facts gained through their experiences. Since experiential factual knowledge and beliefs have not been investigated to date in the misinformation effect literature, simply applying the findings of that literature to the IRD context is inappropriate. Further, as we noted in the introduction and elaborate upon in the next section, the nature of the IRD process makes it highly vulnerable to the misinformation effect.

\section{Theory Development and Hypotheses}

\section{Misinformation Effect and IRD}

The success of the IRD process hinges on two groups: the users who possess the relevant information and the analysts who generally trigger, direct, and control the process (Alvarez 2002; Tan 1994). Using a variety of elicitation techniques, analysts direct users' attention toward relevant and critical issues (Alvarez 2002; Beath and Orlikowski 1994; Davidson 2002; Tan 1994). Given the role of analysts during this process, it is possible that they may introduce, intentionally or unintentionally, misleading or false information. The chance of introducing this misinformation is significant since analysts and users often do not share common mental models and interpretive schemes (Alvarez 2002; Bostrom 1989; Davidson 2002; Orlikowski and Gash 1994; Walz et al. 1993). For example, Davidson (2002) noted that different technological frames of reference of users and analysts direct their attention and cause information to be filtered in particular ways during IRD, ultimately affecting their understanding of the requirements. Also, analysts and users often possess different backgrounds, since analysts are trained in information systems and allied fields while users are trained in functional business domains. Differing mental models, backgrounds, and goals often cause misunderstandings and lead to difficulties in interpreting information conveyed by one person to another, which may result in the unintentional introduction of misinformation (Bednar and Welch 2008). Analysts may also simply make mistakes in their discussions with users that cause misinformation to be introduced unintentionally.

In addition, analysts may intentionally introduce misinformation (sometimes referred to as disinformation; Hernon 1995). When misinformation is introduced intentionally, it is related to the concept of deception (see Buller and Burgoon 1996; DePaulo et al. 2003; Johnson et al. 2001). In IRD, for example, the goals of analysts can lead them to intentionally withhold information or introduce misinformation during the 
IRD process. For instance, while users may desire a userfriendly interface, analysts may focus on compatibility with existing IS infrastructure (Lin and Silva 2005; see also Robey and Markus 1984), and analysts may intentionally introduce misinformation to convince users to agree with analysts' goals. Further, the differing backgrounds and mental models of analysts and users noted above may also cause one party or both (analysts or users - a point to which we return in the "Discussion" section) to exploit the knowledge differences to intentionally introduce misinformation.

The IRD process is particularly vulnerable to the intentional introduction of misinformation because analysts usually have primary control over the process. There are many examples discussed in the literature of opportunities for analysts to use their control to influence user requirements (in a variety of ways, including introducing misinformation). For example, as noted by Alvarez (2002, p. 103),

the analyst is poised to control the interview, ask the questions and determine what gets talked about.... they identify what constitutes information, what gets documented and included as a requirement. They assume the gatekeeper role to some degree which provides them with authority to make decisions about the shape and form of the new information system.

Similar observations have been made by numerous other authors (e.g., Beath and Orlikowski 1994, p. 372; Markus and Bjørn-Andersen 1987, p. 499). Robey and Markus (1984, pp. 10-11) provide a vivid description of the potential for intentional introduction of misinformation by analysts when they control the process:

For example, in performing the feasibility study... systems professionals may strategically state "truths" about project costs and requirements. Their expert knowledge and position in the cycle allows them to represent data about user needs, implementation alternatives, and cost-benefit analyses in ways that may be advantageous for themselves and disadvantageous for users.

There is also case study evidence available concerning analyst-introduced misinformation in systems development practice. For example, Lin and Silva (2005, p. 58) describe the following findings in their case study of the adoption of e-mail software in an organization.

Through engaging the user group in a discussion of the definition of the e-mail system and its technical feasibility, the project team successfully changed the user group's initial choice [BeyondMail] to Group Wise. Our data show that the project team deliberately used abstract concepts and technical jargon to muddy the user group's understanding of the project and their expectations of the new system.

Urquhart (2001) provides a second example of the potential introduction of misinformation. In describing a user's concerns about his relationship with the systems analyst, Urquhart (2001, p. 255) states "he clearly felt at a disadvantage when dealing with an IT section that seemed to use their expertise as a defence." She goes on to quote the user as follows:

there is always this big mystery about what goes on in Information Services and you're really, in a lot of cases, in a take it or leave sort of situation because you don't have the expertise or the knowledge to argue the position and say "it's not that hard, why don't you just do this, this, and this?" You've really got to take it at face value what you're told, and that might be because they simply don't want to do it.

In summary, this background provides ample evidence for the potential occurrence of the misinformation effect during the IRD process. We now use this discussion to develop our first set of hypotheses concerning potential misinformation effects.

We have demonstrated the theoretical vulnerability of the IRD process to misinformation. The prior research on the misinformation effect in the psychology literature described above leads us to hypothesize that analyst-introduced misinformation will result in lower accuracy of information provided by users. Because facts and beliefs are both important aspects of users' domain knowledge, and because the misinformation effect may impact them differently, we have generated separate hypotheses for the two constructs. Therefore, it is hypothesized ${ }^{2}$ that

H1a: In responding to factual questions, users who have received misinformation from analysts are more likely to provide inaccurate answers than those who did not receive any misinformation.

H1b: In responding to belief-related statements, users who have received misinformation from analysts are more likely to provide responses that are aligned with the misinformation than those who did not receive any misinformation.

\footnotetext{
${ }^{2}$ All hypotheses are stated in the alternative form.
} 
Examining the role of the misinformation effect during IRD can provide useful insights into the reasons for inaccurate requirements that are often gathered during systems development. However, to understand the consequences of the misinformation effect and how best to prevent their occurrence, it is important to understand the mechanisms underlying the effect. The next section explores the causes of the misinformation effect identified in the literature and presents relevant hypotheses in the context of this study.

\section{Potential Causes of the Misinformation Effect During the IRD Process}

Although the misinformation effect is well established as a psychological phenomenon, no consensus has emerged regarding its interpretation. There has been considerable debate as to whether people who receive misleading information genuinely believe it. In studying the causes, most researchers have viewed misinformation as either a purely cognitive phenomenon or as a social psychological phenomenon.

Taking a cognitive perspective, Loftus and her colleagues (e.g., Loftus et al. 1989; Loftus et al. 1978) argued that misinformation "updates" the previously formed memory for an event such that the memory trace of the event detail is overwritten and destroyed and the representation of the misinformation becomes an inseparable part of the original memory. They posit that misinformation reduces the person's ability to remember event details and results in memory impairment (Lindsay 1990). The tests used under this paradigm usually involve a three-stage procedure for studying eyewitnesses' reactions to misleading information. Subjects are first shown the visual event (in the form of pictures or video), then receive a narrative that contains misleading suggestions about the event details, and finally take a memory test for those event details (Lindsay 1990). Research has demonstrated that individuals exposed to misleading information are likely to report such misinformation confidently on subsequent memory tests.

The memory impairment hypothesis advocated by Loftus and her colleagues was challenged by subsequent researchers who hypothesized alternative mechanisms that could explain the misinformation effect. McCloskey and Zaragoza (1985) challenged the memory impairment hypothesis based on several different arguments, including a demand effect argument. The demand effect refers to the tendency of participants to respond to stimuli in a manner consistent with what they perceive to be the expectations of the experimenter (Weinberg et al. 1983). Participants often adjust their responses to maintain social desirability. McCloskey and Zaragoza suggested that subjects exposed to misinformation would perform worse than those in a control condition even in the absence of any memory impairment suggested by Loftus et al. (1978). Further, they contended that subjects in the misinformation experiments were often led to believe that the narrative was accurate and/or were told that the narrative was developed by a professor who had carefully viewed the slides. Therefore, simply to demonstrate to the experimenter that they were paying attention during the experiment and remembered the event details from the slides as well as the narrative, or simply to align themselves with the perceived expectations of the experimenter, subjects may base their responses on information they knew was obtained from the narrative (Lindsay 1990; Weingardt et al. 1995). Through a series of empirical studies, McCloskey and Zaragoza claimed to have demonstrated that the memory for an original event is not updated or impaired by the introduction of misinformation. Later researchers concluded that McCloskey and Zaragoza's (1985; Zaragoza et al. 1987) findings were largely the result of the demand effect (e.g., Lindsay 1990; Weingardt et al. 1995).

In an effort to circumvent the demand characteristics issue, Lindsay (1990) developed a new procedure based on what is termed the "logic of opposition" paradigm, which is useful in determining the extent to which demand characteristics contribute to a phenomenon under study. The "opposition" refers to providing subjects with information and then asking them to ignore that information in a subsequent recall task (Lindsay 1990). Lindsay's new procedure involved three phases. The first two phases, showing pictures of the original event and presenting a narrative that contained misinformation about the original event, were similar to previous procedures employed to investigate misinformation. However, during the third phase, which involves the test of memory for details of the original event, subjects were instructed that any information obtained from the narrative was incorrect and should not be reported in the memory test (i.e., subjects were told to ignore the misinformation previously introduced) (Weingardt et al. 1994). Given the warning to ignore the narrative, demand characteristics conflict with genuine memory impairment (Weingardt et al. 1995). That is, demand effects in this case should result in subjects ignoring the misinformation so as to conform to the instructions. However, the results of Lindsay's study revealed that subjects sometimes remembered suggested details without being able to remember their source and based their responses on the misinformation from the narrative despite the warning to ignore such misinformation. These results, along with findings from other research (e.g., Belli 1989; Weingardt et al. 1983; Weinberg et al. 1995), established that the misinformation effect is not simply due to the demand effect and that misinformation has the potential to corrupt an individual's memory for event details. 
Given the findings in other contexts that misinformation may be due to both memory impairment and demand effects, we argue that it is essential to examine both explanations in the IRD context. However, there are differences between other contexts and IRD. Unlike participants in eyewitness memory and other paradigms, users' factual knowledge in the IRD context is often a result of multiple exposures over long periods of time. Thus, we hypothesize that it is unlikely that a user's memory for such factual knowledge will be updated by the introduction of misinformation. However, beliefs are more subjective in nature and relatively more malleable. Thus, misinformation received from a reliable source is more likely to influence one's beliefs. Therefore, it is hypothesized that

H2a: $\quad$ Memory impairment does not explain the influence of misinformation on the accuracy of factual requirements provided by users.

H2b: Memory impairment explains the influence of misinformation on belief-related requirements provided by users.

Based on the theory and findings from the psychology literature, the demand effect is also likely to be present in the IRD context. When the systems analyst controls the process, users are more likely to provide answers that they believe conform to analysts' preferred views (Alvarez 2002; Lin and Silva 2005; Silva and Backhouse 2003). It is possible that users may report misinformation introduced by analysts during IRD despite knowing that it is inconsistent with their true knowledge or beliefs simply to conform to the perceived expectations of the analysts or to avoid appearing to be incompetent (see Alvarez 2002). Thus, we hypothesize that

H3a: $\quad$ The demand effect explains the influence of misinformation on the accuracy of factual requirements provided by users.

H3b: $\quad$ The demand effect explains the influence of misinformation on belief-related requirements provided by users.

\section{Requirements Gathering Techniques and the Misinformation Effect}

As noted in the "Background" section, requirements determination typically involves both social and nonsocial techniques for eliciting requirements. Our next set of hypotheses concerns the potential impact of these differing techniques on requirements when misinformation is present.
Most of the studies examining the misinformation effect have focused on eyewitnesses' memory for information presented using video clips or narratives. However, very few studies have examined the misinformation effect when misinformation is introduced by a "social source," often a confederate who watches the video along with the participant, discusses the details subsequently with him or her, and introduces misinformation during the course of this discussion (Gabbert et al. 2003; Gabbert et al. 2004; Highhouse and Bottrill 1995; Wright et al. 2000). These few studies have found high rates (70 to 75 percent) of conformity with the misinformation in participants' responses. However, these studies also ultimately test for the misinformation effect using only a postevent survey and the focus of inquiry has always been eventrelated information recently viewed by the participant.

The social influence literature provides additional important background for elicitation techniques. It is common for people to assume that information shared during a normal discussion is accurate and truthful (Gabbert et al. 2004; Swann et al. 1982). People also generally want to seem agreeable and likeable to others and to avoid appearing to be a "trouble maker" (Gabbert et al. 2004), a factor often referred to as "social desirability distortion" (Richman et al. 1999). In the context of IRD, since the misinformation may be introduced and subsequently elicited by the same person (the analyst), it seems likely that users will conform to the misinformation introduced as a way to be agreeable. A variety of factors inherent in social techniques could further increase the extent of conformity with misinformation. For instance, in social situations additional information is often conveyed through nonverbal influences such as eye contact and facial expressions, and social cues such as perceived credibility and trustworthiness are often present (Gabbert et al. 2004). These nonverbal cues can unintentionally change the results in a way that is consistent with the expectations of the experimenter (Gabbert et al. 2004; Rosenthal 1969). Gabbert et al. (2004) found that a social technique (watching a video of a robbery with another person - a confederate-present) resulted in more misinformation reported by participants than a nonsocial technique (reading a written description of the robbery with no one else present). Finally, research in information systems and other fields concerning interviews and surveys has shown that the two techniques can yield qualitatively different responses in a variety of contexts (see Cooper and Schindler 2008; Sivo et al. 2005).

In the current study we examine requirements gathering techniques in two ways. First, we investigate the misinformation effect when misinformation is introduced and subsequently elicited using two elicitation techniques: (1) a social technique (a technique that relies on social interaction 
between analyst and user), in this case a structured interview, and (2) a nonsocial technique (a technique in which there is no direct interaction between the analyst and the user), in this case a survey. Both interviews and surveys are commonly used in IRD processes (George et al. 2006; Kendall and Kendall 2010). Thus, in the present study, all factors except the source of misinformation and elicitation mode (social versus nonsocial) will be held constant to examine whether users are influenced more when misinformation is encountered as part of an interview or when using a survey instrument. Based on the findings in the social influence and misinformation effect literatures, we hypothesize that

H4a: $\quad$ The misinformation effect will be greater for factual requirements provided by users when misinformation is introduced and elicited using a social technique (interview) rather than a nonsocial technique (survey).

H4b: The misinformation effect will be greater for beliefrelated requirements provided by users when misinformation is introduced and elicited using a social technique (interview) rather than a nonsocial technique (survey).

Additionally, the requirements elicitation process has two main objectives: to minimize inaccurate requirements and to maximize accurate requirements. While we posit that social techniques are more susceptible to the misinformation effect and therefore more likely to produce inaccurate requirements, it is also important to investigate whether social techniques are more or less likely to generate accurate requirements when misinformation is not present.

Much research supports the view that the personal nature of social techniques such as interviews makes participants pay more attention to the process, encourages them to think about their responses (since they will be responding to someone and will not want to be judged poorly by that person), and makes them feel more accountable for their responses (see Lerner and Tetlock 1999; Levine et al. 1993). Hence, we expect the accuracy of requirements that were not subject to misinformation to be higher with social techniques than with nonsocial techniques. That is, although we expect misinformation to be higher with social techniques (H4a), we also expect people to try harder and thus be more accurate concerning requirements about which they have received no misinformation. This yields our final hypothesis:

H5: A social technique (interview) will result in more accurate requirements for factual items about which participants received no misinformation than a nonsocial technique (survey).
This hypothesis is important to be able to make meaningful recommendations about the selection of elicitation techniques. With these hypotheses in mind, we now turn to the methodology we used to test them.

\section{Methodology}

\section{Pilot Test}

Twenty students participated in a pilot test that was conducted to (1) identify the critical items to be manipulated during the experiment and (2) ensure that subjects understood the instrument and were able to complete it without any problems. The subjects for the pilot test were drawn from the same population as the subjects for the subsequent experiment. All pilot subjects were assigned to the control condition. Ten students were interviewed while the other ten were surveyed. Based on the responses of the participants to the different factual questions and belief-related statements, four "critical" items (two factual items and two belief-related items) were selected for use subsequently as misinformation for the treatment conditions in the experiment. Selection of the critical items was based on the pilot participants' responses. Two factual questions for which most participants answered correctly were chosen as the two critical factual questions. For the two belief-related critical items that were chosen, all of the participants strongly disagreed with the statements. That is, all of the participants rated both the belief-related items either 1 or 2 on a seven-point Likert scale $(1=$ strongly disagree to $7=$ strongly agree $)$. These statements were then included in the treatments, discussed below, because pilot subjects believed otherwise (as shown by their uniformly low ratings of the items), and we were therefore able to use these items to introduce misinformation. None of the students reported any problems during the elicitation session.

\section{Subjects and Design}

A total of 153 students (97 male and 56 female) enrolled in the college of business at a large university participated in the experiment for extra credit. Participation in the study was voluntary. The study employed a 3 (condition: control, memory impairment, demand effect) $\times 2$ (requirements technique: interview, survey) between-subjects design. Each subject was randomly assigned to one of the experimental conditions. Participants in the interview condition took part individually, while those in the survey condition were in a room with 7 to 10 other participants. 


\section{Procedure}

Upon arrival, participants were assigned randomly to one of the conditions and were seated in a chair in a private office or a larger room, depending on the condition. The participants were welcomed by an interviewer who introduced herself as an analyst working with the university's IT department for the Student Information System Upgrade Project (the analyst [interviewer] was a 26-year-old female who wore business casual attire and conducted the interviews in a professional manner). Because she introduced herself as an analyst, conducted the sessions, and provided the instructions, it was clear to participants that she was controlling the process; thus, consistent with the theory and empirical findings noted earlier, the demand effect was expected to be present.

This university uses a student information system that allows students to perform a variety of tasks, such as add and drop classes, view and print class schedules, manage accounts, request transcripts, forward campus e-mail, and view midterm and final grades. The system had not been upgraded for at least four years prior to this study. All subjects participated during a period of two weeks, and no system upgrades occurred during this period. Students are required to register for courses every semester using this system and also to use the system as the primary mode for checking grades, paying fees, purchasing parking tickets, etc. Thus, students are appropriate participants in this study because they are regular users of the system, have current knowledge of the system, and have a real motivation for its improvement. The participants were asked to $\log$ in to the student information system using their personal user name and password. A booklet containing instructions and a series of three short warm-up tasks to be performed on the system were given to the participants. None of these tasks pertained to the questions that were to be used with the participants subsequently. This phase was included to ensure that the participants were familiar with the information system. All participants completed the tasks without any problems.

The participants were then introduced to the purpose of the session. They were told that the university and the system developers were interested in improving the student information system and thus were interested in gathering information and opinions from students, who are the primary users of the system. Participants did not complete consent forms prior to the experimental sessions; they believed they were participating in an actual system upgrade process (consent forms are not required at this university for research exempt from full review by the Human Subjects Committee). During the introduction phase, the participants in the two treatment conditions (memory impairment and demand effect) were provided with misinformation about two factual features of the system and two other pieces of misinformation aimed at influencing their beliefs about the system (participants in the control condition were not supplied with any misinformation). ${ }^{3}$ These four pieces of misinformation were the critical items referred to above. The misinformation suggested that

- Students could pay tuition using a credit card free of charge (whereas in fact they have to pay an additional fee for paying tuition with a credit card)

- The student information system is available 24 hours a day (whereas in fact it is not available from midnight to 7:00 a.m.)

- The student information system has a slow response time (whereas it is generally believed to be a fast systemconfirmed during the pilot test, when pilot subjects all strongly disagreed that it is a slow system)

- The student information system is well utilized by the faculty members (whereas it is generally believed that the faculty members do not use the system effectivelyconfirmed during the pilot test, during which pilot subjects all strongly disagreed that faculty members utilize the system effectively $)^{4}$

After the introduction, participants answered demographic questions and were asked to rate several statements aimed at assessing their familiarity with the information system. Participants were then introduced to the last phase of the session, which contained two sets of questions: first, there were 11 factual questions about the features of the student information system, and, second, there were 13 questions aimed at

\footnotetext{
${ }^{3}$ The misinformation provided concerned the "as-is" system rather than the "to-be" system. Subjects were told explicitly that information was being gathered about the current system to identify current potential problems so they could be addressed in the upgrade of the system. We used the as-is system because users are typically better at articulating information about what they already do than they are at envisioning what a proposed system should do. A new system involves changes of some type (typically to business processes) and causes uncertainty in the minds of users (Joshi 1991). We believe that misinformation effects are likely to be stronger when discussing to-be systems since users are probably less certain about the technologies involved and will thus be more vulnerable to misinformation introduced by analysts (and thus the results of the current study can be considered a lower bound).

${ }^{4}$ All of these critical items are potentially relevant to a system upgrade since they impact usage and perceptions about the current system. Students and faculty use the system for many purposes. Factual questions about the current system are important because if students do not know about current features, it may be because they do not use them or value them. Beliefrelated questions are important because of the impact of perceptions on system usage.
} 
gathering the beliefs of the participants regarding the functionality of the system. Participants answered the first set of questions by indicating yes or no and answered the second set of questions on a seven-point Likert scale $(1=$ strongly disagree to $7=$ strongly agree). Each set of questions contained two critical questions (noted above) that were aimed at studying the effect of misinformation on participants' responses. The use of two critical questions (out of 11 for factual items and 13 for belief-related items) is consistent with past research on the misinformation effect (e.g., Belli 1989; Gabbert et al. 2004; Saunders and MacLeod 2002; Weingardt et al. 1995). The introduction of too much misinformation can raise suspicions in participants about the veracity of the cover story.

The logic of opposition paradigm was employed to test the memory impairment hypothesis (i.e., misinformation updates the initial memories of subjects). Before the final recall phase (the factual and belief-related questions), participants in this condition were instructed that any information obtained during the introductory phase was wrong and should not be reported in the final memory test. Under such opposition instructions, even if demand characteristics are in operation, they will lead the users to prod their memories for correct answers (Weingardt et al. 1995). Accordingly, subjects in the memory impairment treatment condition received the following additional instructions before answering the two sets of questions:

To ensure that you are familiar with the XXX system, we need to ask you some questions. For some of the questions, the answers were not mentioned in the introduction section. For other questions, the answers were mentioned in the introduction section, but were described inaccurately. There is no question on this survey for which the correct answer was provided in the introduction. Therefore, please answer the following questions to the best of your ability without relying on the information provided in the introduction section.

These instructions were adapted from Lindsay (1990) to suit the context of this study. After participants answered the two sets of questions (concerning the fact and belief statements), the interviewer asked them if they would like to provide any other feedback about the system. Participants were then asked to review the information they had provided to the interviewer, make any changes they desired, and sign at the end of the booklet in which the interviewer had recorded their answers. They were then debriefed and thanked for their participation. Sessions with participants generally lasted 20 to 25 minutes.
The participants in the survey condition followed the same procedure but were given booklets with instructions and tasks that they performed by themselves. They had no interaction with the interviewer and misinformation was introduced as a part of the introductory section in the first booklet. Participants were allowed to work through the booklets at their own pace.

All participants, regardless of treatment condition, completed the study in three different sections. Participants in the survey technique completed each booklet, turned it in, and received the next booklet. Participants in the interview technique were read the same materials in three different sections of the interview. Thus, there was no opportunity to refer back to the cover story or any other material during the experimental session.

\section{Coding}

The 11-item questionnaire containing factual questions was scored in terms of the number of neutral questions (noncritical items) answered correctly (yielding a score of 0 to 9 ) and the number of critical questions answered incorrectly (yielding a misinformation score that ranged from 0 to 2). For the factual questions, these numbers were added to create a misinformation score for each participant, which is typical in misinformation effect studies. For the questionnaire containing the belief statements, however, the response numbers were not added. Adding the ratings provided on two different belief statements (system response time and effective use by faculty) could result in a meaningless misinformation score and thus lead to misinterpretation of the results, so the responses were used individually to make within-group and between-group comparisons.

\section{Results}

As noted, to ensure that the participants were familiar with the information system, they were asked to rate their familiarity on a seven-point scale that had anchors of $1=$ completely unfamiliar and $7=$ completely familiar. The average rating for this question was 5.83 (S.D. $=0.91$ ) suggesting that the participants believed themselves to be quite familiar with the system. Participants were also asked to rate their response to a question concerning how often they used the system on a seven-point scale that had anchors of $1=$ very rarely and $7=$ very often. The average rating for this question was 4.58 (S.D. $=1.25$ ) suggesting that the system utilized in the study is commonly used by the participants. Since no participants rated their use of the system as "rarely" (ratings 1 or 2), no one's responses were removed from the analyses. 


\section{Does the Misinformation Effect Occur in the Context of IRD?}

The misinformation scores calculated for all of the conditions were analyzed to determine whether the misinformation effect occurred when participants provided responses to the factual questions. The scores were based on the number of inaccurate responses to the critical factual questions and ranged from 0 (no inaccurate responses) to 2 (both responses were inaccurate). The mean misinformation score was higher for participants in the demand effect condition (mean $=1.51$; S.D. $=0.64$ ) and in the memory impairment condition (mean = 0.94; S.D. $=0.73$ ) than for those in the control condition $($ mean $=0.35 ;$ S.D. $=0.56)($ see Table 1$) . \quad$ Univariate ANOVA was performed to examine the differences between the treatment conditions and the control condition for the misinformation scores. The differences were significant $\left(\mathrm{F}_{(2,152)}=40.493 ; \mathrm{p}<0.001\right)$ and hence H1a was supported.

Table 2 summarizes the means and standard deviations of participants' responses to the two critical belief statements. On a seven-point scale ranging from 1 (totally disagree) to 7 (totally agree), participants in the control condition had lower means, suggesting that they (correctly) disagreed with the two critical belief statements. Participants in the treatment conditions had higher means, suggesting that they were influenced by the misinformation while responding to the critical belief statements. Multivariate ANOVA was used to analyze the differences. The differences were significant for both beliefrelated statements (Item 1: $\mathrm{F}_{(2,152)}=25.92, \mathrm{p}<0.001$; Item 2: $\left.\mathrm{F}_{(2,152)}=21.21, \mathrm{p}<0.001\right)$ and thus H1b was also supported. Therefore, we conclude that the misinformation effect occurs during requirements determination.

Since support for the misinformation effect was found in the responses of participants to both factual questions and beliefrelated statements, further planned comparisons using the Bonferroni procedure were made to understand what causes the misinformation effect. The results of these comparisons were used to test $\mathrm{H} 2 \mathrm{a}, \mathrm{H} 2 \mathrm{~b}, \mathrm{H} 3 \mathrm{a}$, and $\mathrm{H} 3 \mathrm{~b}$, and are discussed in the paragraphs that follow.

\section{Does Memory Impairment Cause the Misinformation Effect?}

Planned comparisons revealed that participants in the memory impairment condition had a significantly higher misinformation score for the factual questions than those in the control condition ( $p<0.001)$. Therefore, H2a (the memory impairment hypothesis does not explain the influence of misinformation on responses to factual questions) was not supported.
We discuss this unanticipated finding in more detail below. Participants in the memory impairment condition reported beliefs more consistent with the misinformation introduced earlier than those in the control condition (Item 1: $p=0.018$; Item 2: $\mathrm{p}=0.003$ ). Therefore $\mathrm{H} 2 \mathrm{~b}$ was supported. Based on these findings, we conclude that memory impairment is one of the causes of the misinformation effect in the context of requirements elicitation.

\section{Does the Demand Effect Cause the Misinformation Effect?}

Participants in the demand effect treatment condition had a significantly higher misinformation score for the factual questions than those in the control condition $(p<0.001)$. Therefore, H3a (demand effect explains the influence of misinformation on responses to factual questions) was supported. Also, participants in the demand effect condition reported beliefs more consistent with the misinformation introduced than those in the control condition (Item 1: $\mathrm{p}<$ 0.001 ; Item 2: $\mathrm{p}<0.001$ ). Therefore $\mathrm{H} 3 \mathrm{~b}$ was also supported. Further, participants in the demand effect condition had a significantly higher misinformation score than those in the memory impairment condition $(p<0.001)$ and reported beliefs more consistent with the misinformation when compared to those in the memory impairment condition (Item 1: $\mathrm{p}<0.001$; Item 2: $\mathrm{p}=0.006$ ). Therefore, we conclude that (1) the demand effect is an important cause of the misinformation effect, and (2) in the context of requirements elicitation, though memory impairment contributes to the observed misinformation effect, the demand effect is the dominant cause of the misinformation effect. ${ }^{5}$

\footnotetext{
${ }^{5}$ It is worth noting that we did not have an independent measure for the demand effect, such as a question to participants about whether they responded to items because they believed the interviewer sought or expected that answer or whether they reported their true beliefs. Early research on the misinformation effect (e.g., Loftus et al. 1978) included such a question on debriefing questionnaires. However, Weinberg et al. (1983) argued that such a question "essentially asks subjects to admit to dishonesty" (p. 102) and therefore is a poor measure of potential demand effects. Thus, subsequent studies typically omitted such questions and relied instead on inferences based on the experimental design. We employed the latter procedure in the current experiment. However, it is important to note that because we did not have an independent measure, we cannot confirm that the theoretical mechanism underlying participants' responses was the demand effect. As in many psychological studies, we infer the demand effect explanation due to the presence of the analyst who controlled the process and the previous literature demonstrating that participants try to conform to the perceived expectations of the experimenter in such situations.
} 


\begin{tabular}{|c|c|c|c|c|}
\hline Technique & Treatment & Mean & Std. Dev. & $\mathbf{N}$ \\
\hline \multirow[t]{4}{*}{ Interview } & Control & .27 & .53 & 26 \\
\hline & Demand Effect & 1.73 & .53 & 26 \\
\hline & Memory Impairment & 1.00 & .75 & 26 \\
\hline & Total & 1.00 & .85 & 78 \\
\hline \multirow[t]{4}{*}{ Survey } & Control & .44 & .58 & 25 \\
\hline & Demand Effect & 1.28 & .68 & 25 \\
\hline & Memory Impairment & .88 & .73 & 25 \\
\hline & Total & .87 & .74 & 75 \\
\hline \multirow[t]{4}{*}{ Total } & Control & .35 & .56 & 51 \\
\hline & Demand Effect & 1.51 & .64 & 51 \\
\hline & Memory Impairment & .94 & .73 & 51 \\
\hline & Total & .93 & .80 & 153 \\
\hline
\end{tabular}

*Note: Misinformation score ranges from 0 to 2 with 0 referring to correct responses to both of the critical factual questions and 2 referring to incorrect responses to both of the critical factual questions.

\begin{tabular}{|l|l|c|c|c|c|c|}
\hline \multirow{2}{*}{ Table 2. Summary Statistics for Critical Belief Statements* } \\
\hline \multirow{2}{*}{ Technique } & \multicolumn{1}{|c|}{ Treatment } & \multicolumn{2}{|c|}{ Mean } & Std. Deviation & N \\
\cline { 2 - 7 } & Belief Items & Item 1 & Item 2 & Item 1 & Item 2 & \\
\hline Interview & Control & 2.46 & 3.65 & 1.39 & 1.85 & 26 \\
\hline & Demand Effect & 5.96 & 6.12 & 1.24 & 1.07 & 26 \\
\hline & $\begin{array}{l}\text { Memory } \\
\text { Impairment }\end{array}$ & 4.58 & 5.50 & 2.02 & .91 & 26 \\
\hline Survey & Total & 4.33 & 5.09 & 2.14 & 1.70 & 78 \\
\hline & Control & 2.96 & 4.00 & 1.62 & 1.35 & 25 \\
\hline & Demand Effect & 4.44 & 5.24 & 1.69 & 1.20 & 25 \\
\hline & Memory & 2.76 & 4.04 & 1.79 & 1.59 & 25 \\
\hline Impairment & Total & 3.39 & 4.43 & 1.84 & 1.49 & 75 \\
\hline & Control & 2.71 & 3.82 & 1.51 & 1.62 & 51 \\
\hline & Demand Effect & 5.22 & 5.69 & 1.65 & 1.21 & 51 \\
\hline & Memory & 3.69 & 4.78 & 2.10 & 1.47 & 51 \\
\hline & Impairment & 3.87 & 4.76 & 2.05 & 1.63 & 153 \\
\hline & Total & & & & \\
\hline
\end{tabular}

${ }^{*}$ Note: Responses were on a 7-point Likert scale $(1=$ strongly agree to $7=$ strongly disagree $)$ 


\section{Misinformation Effect and Elicitation Techniques}

Participants in the interview condition had a mean misinformation score of 1.37 (S.D. $=0.74$ ) and those in the survey condition had a mean misinformation score of 1.08 (S.D. $=$ 0.72). To examine whether this difference is significant, a t-test was conducted on the data from the two treatment conditions with elicitation technique as the independent variable. Data from the control condition were not included for this analysis since those participants did not receive any misinformation. ${ }^{6}$ The difference in the misinformation score was significant, with $\mathrm{t}_{(100)}=1.97 ; \mathrm{p}=0.026$ (one-tailed). Therefore, H4a was supported. That is, the misinformation effect on factual requirements provided by users is greater when misinformation is introduced and elicited using the interview (social) technique than when using the survey (nonsocial) technique.

In responding to the critical items pertaining to beliefs about the system, participants in the interview condition had responses more aligned with the misinformation when compared to those in the survey condition. Participants in the interview condition had mean responses of 5.27 and 5.81 (S.D. $=1.81$ and 1.03 ) to the two critical items while those in the survey condition had mean responses of 3.60 and 4.64 (S.D. $=1.92$ and 1.52) to the two critical items. Results of multivariate ANOVA showed that the differences were significant (Item 1: $\mathrm{F}_{(1,101)}=20.51, \mathrm{p}<0.001$; Item 2: $\mathrm{F}_{(1,101)}$ $=20.74, \mathrm{p}<0.001)$. Therefore, H4b was also supported.

\section{Elicitation Techniques and Facts Not Subject to Misinformation}

To test whether the interview elicitation technique yielded more accurate answers than the survey technique for facts not subject to misinformation, we utilized participants' responses to the nine neutral questions relating to facts about the student information system. Responses to each of these questions were coded as 1 (correct response) or 0 (incorrect response). The total number of correct responses provided to the neutral questions formed each participant's accuracy score.

\footnotetext{
${ }^{6}$ Because the control condition was not included in this analysis, the mean values for the tests in this section do not appear in Tables 1 and 2. The mean values were calculated from the means for the demand effect and memory impairment treatments within each technique (interview and survey). For example, for the interview technique for the factual questions, the mean can be calculated in a shorthand fashion as follows: $(1.73+1.00) / 2=1.37$ (addition of the treatment means and division by 2 is possible since $\mathrm{N}$ is equal for the two treatments).
}

A t-test was performed comparing the accuracy scores for the two groups, interview $($ mean $=8.71$, S.D. $=.54)$ and survey (mean $=7.98$, S.D. $=.89)$. The resulting difference was highly significant $\left(\mathrm{t}_{(100)}=5.05 ; \mathrm{p}<.0001\right)$. Thus, the social interview technique yielded more accurate responses to the items not subject to misinformation than the nonsocial survey technique, supporting H5. Table 3 provides a summary of the hypotheses and results.

\section{Discussion}

Threats to the accuracy of requirements are of fundamental concern in IRD. We have addressed the threat of misinformation on requirements accuracy in this study by focusing on three main issues: Does the misinformation effect occur in the context of gathering requirements about facts and beliefs? If the misinformation effect does occur, what is the underlying mechanism that causes it? Does the requirements gathering technique of interviewing make users more vulnerable to the misinformation effect than the survey technique? This section provides a discussion of these three main issues in terms of both theoretical and practical implications.

\section{Implications for Theory}

Significant differences between responses of the participants in the control and treatment conditions to critical items established that the misinformation effect occurs during IRD.

Misinformation introduced by the analyst influenced users' responses to both factual and belief-related questions irrespective of the elicitation technique employed. The results reveal a new perspective concerning the accuracy of requirements that has not been generally recognized. That is, one reason for inaccurate requirements given by users is likely misinformation provided by analysts.

Further, support for $\mathrm{H} 3 \mathrm{a}$ and $\mathrm{H} 3 \mathrm{~b}$ demonstrates that an important cause of the misinformation effect in the context of IRD is the demand effect. Participants in the demand effect treatment condition performed significantly worse than the other participants. They had a significantly higher misinformation score for factual information and they aligned their beliefs more closely to the misinformation than participants in the other conditions. Further analysis revealed that although memory impairment explains the misinformation effect in IRD, the demand effect provides a stronger explanation. Such patterns were also found when comparing responses of participants for a given elicitation technique. Therefore, we conclude that the misinformation effect in the context of IRD is 
Table 3. Hypotheses and Results Summary

Hypotheses

\section{Between Group Comparisons}

H1a: In responding to factual questions, users who have received misinformation from analysts are more likely to provide inaccurate answers than those who did not receive any misinformation.

$\mathrm{H} 1 \mathrm{~b}$ : In responding to belief-related statements, users who have received misinformation from analysts are more likely to provide responses that are aligned with the misinformation than those who did not receive any misinformation.

H2a: Memory impairment does not explain the influence of misinformation on the accuracy of factual requirements provided by users.

$\mathrm{H} 2 \mathrm{~b}$ : Memory impairment explains the influence of misinformation on the accuracy of belief related requirements provided by users.

H3a: Demand effect explains the influence of misinformation on the accuracy of factual requirements provided by users.

H3b: Demand effect explains the influence of misinformation on the belief related requirements provided by users.

H4a: Misinformation effect on factual requirements provided by users will be greater when misinformation is introduced and elicited using social techniques (interviews) rather than non-social techniques (surveys).

H4b: Misinformation effect on belief related responses provided by users will be greater when misinformation is introduced and elicited using social techniques (interviews) rather than non-social techniques (surveys).

H5: Social techniques (interviews) will result in more accurate requirements (for factual items) about which participants received no misinformation than nonsocial techniques (surveys).

\begin{tabular}{|l|l|}
\hline ANOVA & Supported \\
$F_{(2,152)}=40.49 ; p<0.001$ & \\
\hline $\begin{array}{l}\text { MANOVA } \\
\text { Item 1: } F_{(2,152)}=25.92 ; p<0.001 \\
\text { Item 2: } F_{(2,152)}=21.21 ; p<0.001\end{array}$ & \\
\hline $\begin{array}{l}\text { Pairwise Comparisons } \\
p<0.001\end{array}$ & \\
\hline $\begin{array}{l}\text { Pairwise Comparisons } \\
\text { Item 1: } p=0.018 \\
\text { Item 2: } p=0.003\end{array}$ & Not Supported \\
\hline $\begin{array}{l}\text { Pairwise Comparisons } \\
p<0.001\end{array}$ & \\
\hline $\begin{array}{l}\text { P-Test } \\
t_{(100)}=5.05 ; p<.0001\end{array}$ & \\
\hline $\begin{array}{l}\text { Item 1: } p<0.001 \\
\text { Item 2: } p<0.001\end{array}$ & Supported \\
\hline $\begin{array}{l}\text { T-Test } \\
t_{(100)}=1.97 ; p=0.026 \\
\text { Item 1: } F_{(1,101)}=20.51 ; p<0.001 \\
\text { Item 2: } F_{(1,101)}=20.74 ; p<0.001\end{array}$ \\
\hline Supported \\
\hline
\end{tabular}

primarily due to the demand effect and is further magnified by genuine memory impairment.

These findings provide an integrative theoretical framework for understanding previous work on user-analyst communication. As noted, some research has demonstrated that user participation improves requirements determination and system success (Hunton and Beeler 1997; Hwang and Thorn 1999; Newman and Sabherwal 1996), but findings on the influence of user participation have been equivocal. The misinformation effect may be one important contingency factor that helps explain the differing findings. If analysts intentionally or unintentionally introduce misinformation, they undermine the process of user participation and hence cannot derive benefits from it.

Lack of support for $\mathrm{H} 2 \mathrm{a}$ provides an important perspective on the misinformation effect. We hypothesized that the influence of misinformation on responses to factual questions would not be caused by memory impairment since it is unlikely that memories for factual knowledge gained over a period of time will change with the introduction of misinformation. For example, if a user has seen a feature of a system over and over again, it is unlikely that he will believe misinformation introduced that contradicts his factual knowledge. However, this hypothesis was not supported; factual knowledge learned over 
a period of time was impacted. This finding should be of considerable concern for all systems development stakeholders. To attempt to understand the finding further and be able to suggest potential mitigating strategies, we conducted additional exploratory analysis. Multiple comparisons revealed that among the participants interviewed, participants in the memory impairment condition had significantly higher misinformation scores than those in the control condition ( $\mathrm{p}=0.001)$. However, among the surveyed participants, there was no significant difference in the misinformation scores for factual questions for those participants in the control condition and the memory impairment condition $(p=0.242)$. These additional findings provide important insights. Factual knowledge learned over time was not affected by memory impairment when a survey instrument was utilized, and the misinformation effect did not occur, but memory impairment and the misinformation effect did occur when interviews were utilized. This finding illustrates additional concerns about the impact of interviews on accuracy of recall. We discuss potential mitigating strategies later in this section.

Support for $\mathrm{H} 2 \mathrm{~b}$ demonstrates that irrespective of the technique employed, the memory impairment hypothesis explains the misinformation effect observed in the responses of users to statements of beliefs. As we discuss below, particular care must be taken in elicitation procedures to ensure that suggestive misleading information is not introduced and to be certain that users' true beliefs are assessed.

Support for H4a and H4b suggests an important implication concerning the choice of elicitation techniques. Although interviews conducted with different people are often standardized, it is important to acknowledge that standardization lies on a continuum. At one end, strict standardization is expressed by adherence to prescribed rules and with little flexibility for the interviewer, regardless of the characteristics of the situation. At the other end, interviewer autonomy is evidenced by flexibility in applying a more limited set of rules. The latter is often utilized in cases in which the interviewer needs to clarify a number of factors with the participant. In fact, one of the most important advantages of using the interview technique is the conversational flexibility it provides (Suchman and Jordan 1990). However, this flexibility has both strengths and weaknesses. Interviewer probing can help users understand requests more fully and produce accurate answers, but interviewers can also introduce information that leads users to give inaccurate or unintended responses (Conrad and Schober 1996). Findings of the present study demonstrate that interviews make users more susceptible to misinformation when compared to surveys. In fact, we may have established a powerful boundary condition since probing was not even performed in the current study (if probing had been performed, it would have provided more opportunities for the introduction of misinformation by the analyst). Thus, it is not just misinformation per se that distorts users' responses; rather, the medium by which misinformation is introduced and elicited also has an impact on the magnitude of the misinformation effect. With the social elicitation technique, the effect of misinformation on users' responses is stronger.

However, the results of $\mathrm{H} 5$ demonstrate that the social technique of interviewing leads to higher accuracy of responses to neutral questions (participants in the interview condition were more accurate than participants in the survey condition for neutral factual items). Together, the results of $\mathrm{H} 4$ and $\mathrm{H} 5$ show that interviews lead users to be less accurate for questions about which they have received misinformation (and thus more susceptible to the misinformation effect) when compared to surveys, but more accurate in their responses to factual questions about which they have received no misinformation. The latter, consistent with the theory presented earlier, was presumably a result of greater focus, a stronger feeling of accountability, and trying harder to please the experimenter. On the other hand, surveys lead users to less accurate responses to factual questions about which they have received no misinformation but greater accuracy for misinformation items. In the survey condition, we speculate that the ability to read questions several times and reflect upon them may have led to more accurate answers to the misinformation items, but the lack of social influence (no experimenter present) did not provide the extra motivation to answer the neutral items correctly. This explanation concerning the survey condition is, however, an empirical question.

Thus, the findings from H4 and H5 suggest an important dilemma when it comes to choosing an elicitation technique. Removing interviews from the process reduces the likelihood of analyst-introduced misinformation (although it should be noted that the wording of questions on a survey can also introduce misinformation). Since surveys seem relatively resistant to the misinformation effect, research concerning ways of making them more effective in IRD is important. Our findings provide another reason for using multiple techniques during IRD. Analysts might compare the differences in requirements gathered through interviews and surveys and analyze whether the differences are genuine or are caused by misinformation introduced during the process. Further research into this important dilemma is warranted.

Theoretical implications also exist for alternative forms of requirements gathering. Systems development methods are constantly evolving, and agile methodologies have recently become more widely used. Agile methodologies emphasize an incremental and iterative approach to systems development and thus to requirements elicitation (Boehm 2002; Lee and 
Xia 2010). Each iteration of a system or system component yields a workable output to which users can provide feedback (Baskerville and Pries-Heje 2004). In theory, this approach could reduce misinformation effects that may have occurred during the requirements elicitation process by providing more opportunities for feedback and greater interaction between analysts and users. However, we believe that iterative development will not eliminate the misinformation effect. First, demand effects will still be present and perhaps will be stronger because agile methodologies demand trust among team members and compromise when it comes to deciding which features are important and which are not. Such an environment may make it easier for analysts to influence users' preferences intentionally or unintentionally. Also, a prototype developed by an analyst is a much stronger signal than a textual or verbal suggestion. If an analyst presents a user with a prototype, the user is likely to perceive the prototype as demonstrating the analyst's "expertise" and as a signal that the analyst believes it to be a good solution. This is likely to induce a demand effect. Second, memory impairment indicates that the original knowledge or belief of the user is "overwritten," in which case the original memory is lost and cannot be retrieved even with several iterations. Thus, it seems likely that the misinformation effect will not be eliminated with iterative development techniques. However, this is an empirical question worthy of investigation.

The present research also contributes to theory concerning the misinformation effect in several important ways. As mentioned in the "Introduction" section, the presence of the misinformation effect when dealing with facts and beliefs learned by people over time through experience has not, to our knowledge, been tested before in any context. We found that both types of information were susceptible to the misinformation effect, extending the impact of the effect from the traditional contexts of eyewitness testimony and autobiographical events to contexts in which people have wellestablished knowledge structures in place. The fact that both experientially learned information and beliefs are impacted by the misinformation effect demonstrates the generality of the phenomenon and opens many additional avenues of research in requirements elicitation and human memory more generally. We have also contributed to an improved understanding of the misinformation effect by providing the first test of the phenomenon when information was both introduced and elicited using social (interview) and nonsocial (survey) techniques. ${ }^{7}$ As noted, our findings demonstrate the

\footnotetext{
${ }^{7}$ As noted earlier, Gabbert et al. (2004) elicited information using social (a confederate) and nonsocial (a narrative) techniques but did not introduce the misinformation using social techniques. Their experiment used the standard video clip stimulus in the eyewitness memory paradigm and introduced misinformation using written narratives for all conditions. Our study extends and expands upon the findings of Gabbert et al. (2004).
}

increased impact of the misinformation effect but also the increased accuracy for neutral factual items in interview settings. Our findings suggest that the magnitude of the misinformation effect in traditional contexts such as eyewitness testimony may be even greater if social elicitation techniques are utilized (and thus greater precautions should be taken to prevent the effect from impacting testimony). Further research on these differences is warranted. Thus, the present research adds significantly to the theory concerning the misinformation effect.

\section{Implications for Practice}

Several important implications for practice are suggested by this research. One of the major problems likely to result from the misinformation effect is that organizations develop systems that do not meet their requirements. They may pay for features they do not need, find that systems they develop are not compatible with their existing systems or business processes, or discover that requirements were omitted that would have been useful for the organization. These implications suggest that alerting both systems analysts and project managers to the possibility of the misinformation effect, and using strategies to minimize the effect, are important practical prescriptions.

As noted above, choice of elicitation technique is an important concern given the relative strengths and weaknesses of interviews and surveys for the accuracy of information provided by users. If analysts utilize interviews, they need to take measures to minimize introduction of the demand effect during requirements elicitation. For example, using ethnographers trained in remaining neutral during requirements elicitation could be useful in reducing the demand effect as long as users do not regard them as systems development experts (Smith and Ellsworth 1987). Further, probing using neutral questions, using feedback only to reward complete responses (not the content of responses), and not providing cues to users about how they should respond (Fowler 2009) could significantly reduce the misinformation effect. Analysts should also be careful when discussing opinions or indicating stances on topics during the early stages of eliciting requirements. Although part of natural discourse between people, such information may inappropriately influence or mislead users. At some point, the analyst typically must bring his knowledge of systems design into conversations with users to ensure feasibility of options and to manage user expectations appropriately. However, this intertwining of analysis and design should ideally be left until as late in the elicitation process as possible. In addition to unintentional introduction of misinformation, it may also be difficult to 
control for misinformation introduced intentionally by analysts. From an organizational standpoint, it may be desirable to use surveys for at least some portion of the IRD process, since both intentional and unintentional introduction of misinformation can be reduced with surveys.

An argument can be made that judicious use of misinformation by analysts may lead to some positive outcomes. For example, analysts may provide inaccurate cues (intentionally or unintentionally) that cause users to think of ideas or alternatives or ways of looking at problems that they had not thought of before. Analysts may also intentionally employ misinformation to control "requirements creep," in which the size of the project grows because of continual additions of new requirements (especially ones not absolutely necessary) by users. In such a case, analysts may misinform users about constraints that limit such requirements. Analysts may also intentionally provide misinformation to keep a project on schedule or on budget, which potentially adds value to the organization. However, in addition to ethical considerations involved in intentionally delivering misinformation, there are broader implications for systems development. For example, who should have the ultimate power to decide upon and/or limit requirements? If analysts use their expertise to mislead users into, say, believing that certain requirements cannot be fulfilled, is this in the best interests of the organization? Does this tilt the power too far toward the IS group and away from users? These are both philosophical and practical questions that do not have easy answers.

Another practical issue is that the nature of "users" has changed in some ways over the past few years. For example, users may in some instances be characterized more accurately as "clients"- customers, potential customers, or supplierswho may exert considerable control over the systems development process in general and requirements determination in particular (e.g., Gulliksen et al. 2003; Kirsch et al. 2002; Mouakket et al. 1994). Specific examples include companies (the users) that have outsourced or off-shored systems development work to other firms (the analysts) (e.g., Sakthivel 2007) and retailers such as Wal-Mart that directly influence aspects of the systems development of companies that supply them (e.g., Angeles 2005). In such cases, clients may have substantial influence over the requirements elicitation process. However, even when user-clients direct the process, the analyst remains the person who must ultimately understand and model the requirements to build the system. He thus retains some de facto control over the process in such cases. From a practical standpoint, the misinformation effect may still occur during analyst-user communication and negotiation processes despite these different systems development conditions. With off-shoring, there may be the opportunity for misinformation (intentional or unintentional) to be introduced due to cultural differences and the physical distance between the analysts and clients. With outsourcing, technical expertise may be leveraged by the outsourcing firm to introduce misinformation as part of increasing sales of features or system modules. Thus, contemporary systems development practice, with its more diverse forms, still requires its actors to be vigilant concerning the misinformation effect.

It also may be argued that flaws in information requirements caused by the misinformation effect can be corrected by other steps or strategies in the systems development process. It is possible that structural strategies (such as asking users or analysts to play devil's advocate or using more experienced users) or JAD sessions may make the misinformation effect less likely to occur, or that the requirements verification process (prior to design) or prototyping or testing may expose inaccurate requirements. These are all empirical questions at this point. We note, however, that if misinformation is introduced, memory impairment can cause the original information to be overwritten, so it cannot be recalled later regardless of technique or number of iterations. And, as noted, demand effects will also make the misinformation effect difficult to overcome.

\section{Limitations and Future Research}

The present study has investigated the misinformation effect as a central issue in requirements elicitation efforts. Since this is the first study to address this issue, there are some limitations that should be discussed. However, given the presence of the misinformation effect in this context, the limitations of this study can also serve as fertile ground for further research. Participants in this study were regular users of the system, but were not domain experts. Participants in actual IRD contexts may have differing levels of experience and/or expertise (they may have more or may have less than our participants), which may affect the results obtained. Therefore, examining whether experience and expertise moderate the influence of misinformation on the accuracy of requirements gathered could have important implications for participant selection strategies for IRD. Also, this study did not investigate whether the misinformation effect is temporary or permanent. If the effect is temporary, there may be mitigating strategies analysts can employ, such as introducing breaks during requirements elicitation sessions or gathering requirements over multiple sessions. However, there is evidence from other contexts that the misinformation effect is not temporary (e.g., Marsh et al. 2003), which would be expected considering that memory impairment is one of its causes. And, given that the demand effect is also an important cause, 
the misinformation effect seems unlikely to disappear in IRD. Further, it is also worth noting that beliefs may be more or less malleable. We did not measure strength of beliefs in the present research, but since our results suggest that both facts and beliefs are influenced by demand effects and memory impairment, strength of belief may make no difference. However, investigating the misinformation effect with more strongly held beliefs than those in the current study represents an interesting area for future research.

Another important consideration is that the motivation levels of different organizational stakeholders are likely to range from quite low to quite high under various circumstances. Users whose jobs or work processes will change significantly may have higher motivation and greater focus than people whose work is peripherally affected. Analysts working on higher priority systems development efforts may have higher motivation. And systems that are critical to the mission or survival of the organization should command greater attention and focus than other systems. The system used in this study was not one for which failure would result in disastrous consequences. Although the student participants are real users of this system and have a stake in its proper functioning and planned upgrades, it must be acknowledged that both users and analysts may have greater motivation for a system controlling users' personal security or one ensuring the proper functioning of a nuclear power plant. In the present study, because of the random assignment of participants, we can assume that any motivational differences in participants were distributed evenly across treatment groups. Nonetheless, future research investigating the impact of motivations of organizational stakeholders on the misinformation effect in IRD would be valuable.

We also acknowledge that there is more complexity in the accuracy of requirements using interviews and surveys than we have captured in the present research. For example, users responding to questions from an interviewer often do not have the luxury of thinking carefully and deliberately about a response before providing an answer. In addition, they are not likely to ask the analyst (interviewer) to repeat the question on numerous occasions. In contrast, as noted above, users responding to a survey may both think carefully and reread questions (although whether they do so in requirements elicitation settings is an empirical question). In the present study, this factor may help explain the findings that surveys are somewhat more robust to the misinformation effect.

An important area for future research concerns misinformation introduced into the IRD process by users. Although we focused on analysts in the current research, users are typically the content experts for software applications and analysts must rely on them for accurate requirements. Misinformation introduced by users, either intentionally or unintentionally, is therefore a threat to requirements accuracy and successful systems development. For example, Gallivan and Keil (2003) and Markus and Benjamin (1997) discuss numerous reasons that users are not motivated to provide accurate requirements, including not wanting to challenge strong organizational assumptions and providing feedback on minor technical issues to mask their true desire not to change their work processes. Thus, understanding user-introduced misinformation represents an important area for future investigations.

Future research can also examine additional causes of the demand effect. In the present research we investigated the demand effect as it has traditionally been used in the psychology literature, in this case as a consequence of attempting to meet the expectations of an analyst who was in control of the process. In addition to this cause, there may be other factors that can induce the demand effect. For example, another potential factor is the perceived technical expertise of the analyst. Users may agree with the analyst's suggestions during IRD because they view the analyst as an expert in systems development (see Lin and Silva 2005). In the context of eyewitness memory Smith and Ellsworth (1987) found that misinformation decreased witness accuracy when the questioner was assumed by the subject to be knowledgeable about the crime, but had no effect on accuracy when the questioner was assumed to be naïve. Thus, if a systems analyst is perceived as particularly knowledgeable concerning the topic of interest, users may provide requirements consistent with those suggested by the analyst. Therefore, the results of the current experiment may underrepresent a typical demand effect when compared to traditional IS development settings. In organizational settings in which there is a larger perceived technical expertise gap between users and analysts, the likelihood of analyst-introduced misinformation is expected to be higher. This is an empirical question worthy of additional research.

\section{Conclusion}

The present study has demonstrated that the misinformation effect is a significant threat to the accuracy of requirements gathered for organizational systems. We have extended misinformation effect theory by showing the impact of the effect on factual and belief-related information learned experientially over time, and have found that misinformation introduced by analysts during IRD negatively influences the accuracy of requirements elicited. The misinformation effect is thus central to our understanding of requirements elicita- 
tion. If information gathered is not accurate, the IRD process will fail and the misinformation will negatively affect the success of the full systems development and implementation process. We have introduced a new theoretical perspective to understand why requirements provided by users may not reflect their true knowledge or beliefs. It is important to realize that if analysts introduce misinformation during the requirements elicitation process, the requirements gathered are likely to be a reflection of what the analysts suggest rather than the true requirements of the users. Further research into this important area of systems development is warranted.

\section{Acknowledgments}

The authors thank the senior editor, the associate editor, and three reviewers for their exceptionally helpful comments on this manuscript. We also thank Eric Walden, Donald Jones, Darcy Reich, Amanda Cowen, Vidhya Mellarkod, and the participants at the AMCIS Special Interest Group on Systems Analysis and Design (SIGSAND) Symposium for their useful comments on previous versions of this paper. The second author also thanks Gordon Davis for his foundational work on cognitive aspects of requirements determination that helped lead the way. This research was supported in part by the Rawls College of Business at Texas Tech University and by the MacGill Research Fund at the McIntire School of Commerce at the University of Virginia.

\section{References}

Agarwal, R., and Tanniru, M. 1990. "Knowledge Acquisition Using Structured Interviewing: An Empirical Investigation," Journal of Management Information Systems (7:1), pp. 123-140.

Alvarez, R. 2002. "Confessions of an Information Worker: A Critical Analysis of Information Requirements Discourse," Information and Organization (12:2), pp. 85-107.

Angeles, R. 2005. "RFID Technologies: Supply-Chain Applications and Implementation Issues," Information Systems Management (22:1), pp. 51-65.

Baskerville, R., and Pries-Heje, J. 2004. "Short Cycle Time Systems Development." Information Systems Journal (14:3), pp. 237-264.

Beath, C. M., and Orlikowski, W. J. 1994. "The Contradictory Structure of Systems Development Methodologies: Deconstructing the IS-User Relationship in Information Engineering," Information Systems Research (5:4), pp. 350-377.

Beck, K. 1999. Extreme Programming Explained, Reading, MA: Addison-Wesley Professional.

Bednar, P. M., and Welch, C. 2008. "Bias, Misinformation and the Paradox of Neutrality," Informing Science: The International Journal of an Emerging Transdiscipline (11), pp. 85-106.

Bekerian, D. A., and Bowers, J. M. 1983. "Eyewitness Testimony: Were We Misled?," Journal of Experimental Psychology: Learning, Memory, \& Cognition (9:1), pp. 139-145.
Belli, R. F. 1988. "Color Blend Retrievals: Compromise Memories or Deliberate Compromise Responses?," Memory \& Cognition (16:4), pp. 314-326.

Belli, R. F. 1989. "Influences of Misleading Postevent Information: Misinformation Interference and Acceptance," Journal of Experimental Psychology: General (118:1), pp. 72-85.

Best, J. 1989. Cognitive Psychology, St. Paul, MN: West Publishing.

Boehm, B. 2002. "Get Ready for Agile Methods, with Care." IEEE Computer (35:1), pp. 64-69.

Bonto, M. A., and Payne, D. G. 1991. "Role of Environmental Context in Eyewitness Memory," American Journal of Psychology (104:1), pp. 117-134

Bostrom, R. P. 1989. "Successful Application of Communication Techniques to Improve the Systems Development Process," Information and Management (16:5), pp. 279-295.

Braun, K. A., and Loftus, E. F. 1998. "Advertising's Misinformation Effect," Applied Cognitive Psychology (12:6), pp. 569-591.

Browne, G. J., and Ramesh, V. 2002. "Improving Information Requirements Determination: A Cognitive Perspective," Information and Management (39:8), pp. 625-645.

Buller, D. B., and Burgoon, J. K. 1996. "Interpersonal Deception Theory," Communication Theory (6:3), pp. 203-242.

Burton, A. M., Shadbolt, N. R., Hedgecock, A. P., and Rugg, G. 1987. A Formal Evaluation of Knowledge Elicitation Techniques for Expert Systems: Domain 1 Research and Development in Expert Systems IV, Cambridge, UK: Cambridge University Press.

Byrd, T. A., Cossick, K. L., and Zmud, R. W. 1992. "A Synthesis of Research on Requirements Analysis and Knowledge Acquisition Techniques," MIS Quarterly (16:1), pp. 117-138.

Ceci, S. J., Toglia, M. P., and Ross, D. F. 1988. "On Remembering... More or Less: A Trace Strength Interpretation of Developmental Differences in Suggestibility," Journal of Experimental Psychology: General (117:2), pp. 201-203.

Conrad, F. G., and Schober, M. F. 1996. "How Interviewers' Conversational Flexibility Affects the Accuracy of Survey Data,"in Proceedings of the Annual Meetings of the American Statistical Association, Section on Survey Research Methods, Alexandria, VA: American Statistical Association, pp. 883-888.

Cooper, D. R., and Schindler, P. S. 2008. Business Research Methods, New York: McGraw-Hill.

Cowley, E., and Janus, E. 2004. "Not Necessarily Better, But Certainly Different: A Limit to the Advertising Misinformation Effect on Memory," Journal of Consumer Research (31:1), pp. 229-235.

Davidson, E. J. 2002. "Technological Frames and Framing: A Socio-Cognitive Investigation of Requirements Determination," MIS Quarterly (26:4), pp. 329-358.

Davis, G. B. 1982. "Strategies for Information Requirements Determination," IBM Systems Journal (21:1), pp. 4-30.

DePaulo, B. M., Kashy, D., Kirkendol, S. E., Wyer, M. M., and Epstein, J. A. 1996. "Lying in Everyday Life," Journal of Personality and Social Psychology (70:5), pp. 979-995.

DePaulo, B. M., Lindsay, J. J. Malone, B. E., Muhlenbruck, L., Charlton, K., and Cooper, H. 2003. "Cues to Deception," Psychological Bulletin (129:1), pp. 74-118. 
Fowler, F. J. 2009. Survey Research Methods, Thousand Oaks, CA: Sage Publications.

Fox, C. J. 1993. Information and Misinformation: An Investigation of the Notions of Information, Misinformation, Informing, and Misinforming, Westport, CT: Greenwood Press.

Gabbert, F., Memon, A., and Allan, K. 2003. "Memory Conformity: Can Eyewitnesses Influence Each Other's Memories for an Event?," Applied Cognitive Psychology (17:5), pp. 533-543.

Gabbert, F., Memon, A., Allan, K., and Wright, D. B. 2004. "Say it to My Face: Examining the Effects of Socially Encountered Misinformation, ” Legal \& Criminalogical Psychology (9:2), pp. 215-227.

Gallivan, M. J., and Keil, M. 2003. "The User-Developer Communication Process: A Critical Case Study," Information Systems Journal (13:1), pp. 37-68.

George, J. F., Batra, D., Valacich, J. S., and Hoffer, J. A. 2006. Object-Oriented Systems Analysis and Design, Upper Saddle River, NJ: Pearson Prentice-Hall.

Goguen, J. A., and Linde, C. 1993. "Techniques for Requirements Elicitation," in Proceedings of the IEEE International Symposium on Requirements Engineering, pp. 152-164.

Gulliksen, J., Göransson, B., Boivie, I., Blomkvist, S., Persson, J., and Cajander, Å. 2003. "Key Principles for User-Centred Systems Design," Behaviour and Information Technology (22:6), pp. 397-409.

Hanssen, G. K., and Faegre, T. E. 2008. "Process Fusion: An Industrial Case Study on Agile Software Product Line Engineering," Journal of Systems and Software (81:6), pp. 843-854.

Hartwick, J., and Barki, H. 1994. "Explaining the Role of User Participation in Information System Use," Management Science (40:4), pp. 440-465.

Hartwick, J., and Barki, H. 2001. "Communication as a Dimension of User Participation," IEEE Transactions on Professional Communication (44:1), pp. 21-36.

He, J., and King, W. R. 2008. "The Role of User Participation in Information Systems Development: Implications from a MetaAnalysis," Journal of Management Information Systems (25:1), pp. 301-331.

Hernon, P. 1995. "Disinformation and Misinformation Through the Internet: Findings of an Exploratory Study," Government Information Quarterly (12:2), pp. 133-139.

Hickey, A., and Davis, A. 2004. “A Unified Model of Requirements Elicitation," Journal of Management Information Systems (20:4), pp. 65-85.

Highhouse, S., and Bottrill, K. V. 1995. "The Influence of Social (Mis)Information on Memory for Behavior in an Employment Interview," Organizational Behavior and Human Decision Processes (62:2), pp. 220-229.

Hunton, J. E., and Beeler, J. D. 1997. "Effects of User Participation in Systems Development: A Longitudinal Field Experiment," MIS Quarterly (21:4), pp. 359-388.

Hwang, M. I., and Thorn, R. G. 1999. "The Effect of User Engagement on System Success: A Meta-Analytical Integration of Research Findings," Information \& Management (35:4), pp. 229-236.
Jain, H., Vitharana, P., and Zahedi, F. 2003. "An Assessment Model for Requirements Identification in Component-Based Software Development," Data Base (34:4), pp. 48-63.

Johnson, H. 1994. "Process of Successful Intentional Forgetting," Psychological Bulletin (116:2), pp. 274-292.

Johnson, P. E., Grazioli, S., Jamal, K., and Berryman, R. G. 2001. "Detecting Deception: Adversarial Problem Solving in a Low Base-Rate World," Cognitive Science (25:3), pp. 355-392.

Joshi, K. 1991. "A Model of User's Perspective on Change: The Case of Information Systems Technology Implementation," MIS Quarterly (15:2), pp. 229-242.

Kendall, K. E., and Kendall, J. E. 2010. Systems Analysis and Design, Upper Saddle River, NJ: Prentice-Hall.

Kirsch, L. J., Sambamurthy, V., Ko, D.-G., and Purvis, R. L. 2002. "Controlling Information Systems Development Projects: The View from the Client," Management Science (48:4), pp. 484-498.

Lee, G., and Xia, W. 2010. "Towards Agile: An Integrated Analysis of Quantitative and Qualitative Field Data on Software Development Agility," MIS Quarterly (34:1), pp. 87-114.

Lerner, J. S., and Tetlock, P. E. 1999. "Accounting for the Effects of Accountability," Psychological Bulletin (125:2), pp. 255-275.

Levine, J. M., Resnick, L. B., and Higgins, E. T. 1993. "Social Foundations of Cognition," Annual Review of Psychology (44:1), pp. 585-612.

Light, M. 2009. "How the Waterfall Methodology Adapted and Whistled Past the Graveyard," Gartner Research Report \# G00173423, December 18.

Lin, A., and Silva, L. 2005. "The Social and Political Construction of Technological Frames," European Journal of Information Systems (14:1), pp. 49-59.

Lindsay, D. S. 1990. "Misleading Suggestions Can Impair Eyewitnesses' Ability to Remember Event Details," Journal of Experimental Psychology: Learning, Memory, and Cognition (16:6), pp. 1077-1083.

Liou, Y. I., and Chen, M. 1994. "Using Group Support Systems and Joint Application Development for Requirements Specification," Journal of Management Information Systems (10:3), pp. 25-41.

Loftus, E. F. 1979. "Reactions to Blatantly Contradictory Information," Memory and Cognition (7:5), pp. 368-374.

Loftus, E. F. 2005. "Planting Misinformation in the Human Mind: A 30-Year Investigation of the Malleability of Memory," Learning \& Memory (12:4), pp. 361-366.

Loftus, E. F., Donders, K., Hoffman, H. G., and Schooler, J. W. 1989. "Creating New Memories that are Quickly Assessed and Confidently Held," Memory and Cognition (17:5), pp. 607-616.

Loftus, E. F., Miller, D. G., and Burns, H. J. 1978. "Semantic Integration of Verbal Information into a Visual Memory," Journal of Experimental Psychology: Human Learning and Memory (4:1), pp. 19-31.

Markus, M. L., and Benjamin, R. I. 1997. "The Magic Bullet Theory of IT-Enabled Transformation," Sloan Management Review (38:2), pp. 55-68.

Markus, M. L., and Bjørn-Andersen, N. 1987. "Power Over Users: Its Exercise By Systems Professionals." Communications of the ACM (30:6), pp. 498-504. 
Marsh, E. J., Meade, M. L., and Roediger III, H. L. 2003. "Learning Fact from Fiction," Journal of Memory and Language (49:4), pp. 519-536.

McCloskey, M., and Zaragoza, M. 1985. "Misleading Postevent Information and Memory for Events: Arguments and Evidence Against Memory Impairment Hypotheses," Journal of Experimental Psychology: General (114:1), pp. 1-16.

McKeen, J. D., Guimaraes, T., and Wetherbe, J. C. 1994. "The Relationship Between User Participation and User Satisfaction: Investigation of Four Contingency Factors," MIS Quarterly (18:4), pp. 27-45.

Moody, J. W., Blanton, J. E., and Cheney, P. H. 1998. “A Theoretical Approach to Assist Memory Recall During Information Requirements Determination," Journal of Management Information Systems (15:1), pp. 79-98.

Mouakket, S. Sillince, J. A. A., and Fretwell-Downing, F. A. 1994. "Information Requirements Determination in the Software Industry: A Case Study," European Journal of Information Systems (3:2), pp. 101-111.

Myers, M. D., and Young, L. W. 1997. "Hidden Agendas, Power and Managerial Assumptions in Information Systems Development: An Ethnographic Study," Information Technology and People (10:3), pp. 224-240.

Neisser, U. 1981. "John Dean's Memory: A Case Study," Cognition $(9: 1)$, pp. 1-22.

Newman, M., and Noble, F. 1990. "User Involvement as an Interaction Process," Information Systems Research (1:1), pp. 89-113.

Newman, M., and Sabherwal, R. 1996. "Determinants of Commitment to Information Systems Development: A Longitudinal Investigation," MIS Quarterly (20:1), pp. 23-54.

Norton, D. 2008. "The Current State of Agile Method Adoption," Gartner Research Report \# G00163591, December 12.

Orlikowski, W. J., and Gash, D. G. 1994. "Technology Frames: Making Sense of Information Technology in Organizations," ACM Transactions on Information Systems (12:2), pp. 174-207.

Richman, W. L., Kiesler, S., Weisband, S., and Drasgow, F. 1999. "A Meta-Analytic Study of Social Desirability Distortion in Computer-Administered Questionnaires, Traditional Questionnaires, and Interviews," Journal of Applied Psychology (84:5), pp. 754-775.

Robertson, S., and Robertson, J. 1999. Mastering the Requirements Process, Harlow, U.K.: ACM Press.

Robey, D., Farrow, D., and Franz, C. R. 1989. "Group Process and Conflict During System Management," Management Science (35:10), pp. 1172-1191.

Robey, D., and Markus, M. L. 1984. "Rituals in Information System Design,” MIS Quarterly (8:1), pp. 5-15.

Rosenthal, R. 1969. "Interpersonal Expectations: Effects of the Experimenter's Hypothesis," in Artifacts in Behavioral Research, R. Rosenthal and R. L. Rosnow (eds.), New York: Academic Press, pp. 181-277.

Sakthivel, S. 2007. "Managing Risk in Offshore Systems Development," Communications of the ACM (50:4), pp. 69-75.

Saunders, J., and MacLeod, M. D. 2002. "New Evidence on the Suggestibility of Memory: The Role of Retrieval-Induced Forgetting in Misinformation Effects," Journal of Experimental Psychology: Applied (8:2), pp. 127-142.
Schooler, J. W., and Tanaka, J. W. 1991. "Composites, Compromises, and CHARM: What is the Evidence for Blend Memory Representations?," Journal of Experimental Psychology: General (120:1), pp. 96-100.

Silva, L., and Backhouse, J. 2003. "The Circuits-of-Power Framework for Studying Power in Institutionalization of Information Systems," Journal of the Association for Information Systems (4:6), pp. 294-336.

Sivo, S. A., Saunders, C., Chang, Q., and Jiang, J. J. 2006. "How Low Should You Go? Low Response Rates and the Validity of Inference in IS Questionnaire Research," Journal of the Association for Information Systems (7:6), pp. 351-414.

Smith, V. L., and Ellsworth, P. C. 1987. "The Social Psychology of Eyewitness Accuracy: Misleading Questions and Communicator Expertise," Journal of Applied Psychology (72:2), pp. 294-300.

Suchman, L., and Jordan, B. 1990. "Interactional Troubles in Faceto-Face Survey Interviews," Journal of the American Statistical Association (85:409), pp. 232-241.

Swann, W. B., Giuliano, T., and Wegner, D. M. 1982. "Where Leading Questions Can Lead: The Power of Conjecture in Social Interaction," Journal of Personality and Social Psychology (42:6), pp. 1035-1045.

Tajfel, H., and Turner, J. C. 1986. "The Social Identity Theory of Inter-Group Behavior," in Psychology of Inter-Group Relations $\left(2^{\text {nd }}\right.$ ed.), S. Worchel and W. G. Austin (eds.), Chicago: Nelson-Hall, pp. 7-24.

Tan, M. 1994. "Establishing Mutual Understanding in Systems Design: An Empirical Study," Journal of Management Information Systems (10:4), pp. 159-182.

Urquhart, C. 2001. "Analysts and Clients in Organisational Contexts: A Conversational Perspective," Journal of Strategic Information Systems (10:3), pp. 243-262.

Valusek, J., and Fryback, D. 1987. "Information Requirements Determination: Obstacles Within, Among and Between Participants," in Information Analysis: Selected Readings, R. Galliers (ed.), Reading, MA: Addison-Wesley, pp. 139-151.

Wagenaar, W. A., and Boer, J. P. A. 1987. "Misleading Postevent Information: Testing Parameterized Models of Integration in Memory," Acta Psychologica (66:3), pp. 291-306.

Walz, D. B., Elam, J. J., and Curtis, B. 1993. "Inside a Software Design Team: Knowledge Acquisition, Sharing, and Integration," Communications of the ACM (36:10), pp. 63-77.

Weinberg, H. I., Wadsworth, J., and Baron, R. S. 1983. "Demand and the Impact of Leading Questions on Eyewitness Testimony," Memory \& Cognition (11:1), pp. 101-104.

Weingardt, K. R., Loftus, E. F., and Lindsay, D. S. 1995. "Misinformation Revisited: New Evidence on the Suggestibility of Memory," Memory \& Cognition (23:1), pp. 72-82.

Weingardt, K. R., Toland, H. K., and Loftus, E. F. 1994. "Reports of Suggested Memories: Do People Truly Believe Them?," in Adult Eyewitness Testimony: Current Trends and Developments, D. F. Ross, J. D. Read, and M. P. Toglia (eds.), Cambridge, UK: Cambridge University Press, pp. 3-26.

Wetherbe, J. C. 1991. "Executive Information Requirements: Getting It Right," MIS Quarterly (15:1), pp. 51-65. 
Wright, D. B., Self, G., and Justice, C. 2000. "Memory Conformity: Exploring Misinformation Effects When Presented By Another Person," British Journal of Psychology (91:2), pp. 189-202.

Zaragoza, M. S., McCloskey, M., and Jamis, M. 1987. "Misleading Postevent Information and Recall of the Original Event: Further Evidence Against the Memory Impairment Hypothesis," Journal of Experimental Psychology: Learning, Memory, \& Cognition (13:1), pp. 36-44.

Zhou, L., and Zhang, D. 2007. "An Ontology-Supported Misinformation Model: Toward a Digital Misinformation Library," IEEE Transactions on Systems, Man, and Cybernetics-Part A (37:5), pp. 804-813. 